https://doi.org/10.15407/ujpe65.1.50

O.M. ALEKSEEV, YU.F. ZABASHTA, V.I. KOVALCHUK, M.M. LAZARENKO, E.G. RUDNIKOV, L.A. BULAVIN

Taras Shevchenko National University of Kyiv, Faculty of Physics (64/13, Volodymyrs'ka Str., Kyiv 01601, Ukraine)

\title{
STRUCTURAL TRANSITION IN DILUTE SOLUTIONS OF ROD-LIKE MACROMOLECULES
}

\begin{abstract}
On the basis of experimental data obtained for the viscosity in aqueous solutions of hydroxypropyl methylcellulose (metolose), it has been found that a structural transition takes place in dilute solutions of rod-like macromolecules with the increasing temperature. Namely, macromolecules form clusters in which they are arranged in parallel to one another. It is shown that this transition is a set of local phase transitions of the first kind.

Ke ywords: metolose, cluster, structural transition.
\end{abstract}

\section{Introduction}

The term "rod-like" is known to be used for the description of molecules whose shape is characterized by the inequality

$M_{z} \gg\left(M_{x}, M_{y}\right)$,

where $M_{z}, M_{x}$, and $M_{y}$ are the principal moments of inertia of the molecule. It is also known [1] that if the volume fraction $C$ of such molecules satisfies the condition

$C \sim 1$

the molecules try to form an ordered structure by arranging in parallel to one another. An example of such a structure is the nematic phase of liquid crystals [1].

However, there is an idea that an ordered phase can also be formed in systems of rod-like molecules for which another, different from Eq. (2), condition is obeyed,

$C \ll 1$.

(C) O.M. ALEKSEEV, YU.F. ZABASHTA, V.I. KOVALCHUK, M.M. LAZARENKO, E.G. RUDNIKOV, L.A. BULAVIN, 2020
This opinion was expressed in work [2]. In particular, such systems may undergo a structural transition from a phase with disordered rods into an ordered phase with the rods oriented in parallel to one another. In work [2], it was also shown that this transition is a phase transition of the first kind.

The aim of this work consists in an experimental detection of this structural transition and the determination of its specific features. This task will be implemented by taking a solution with the following characteristics as a model system: (i) the solute consists of rod-like molecules for which condition (3) is satisfied; and (ii) the solvent consists of molecules for which the inequality

$M_{z} \gg\left(m_{x}, m_{y}, m_{z}\right)$,

where $m_{x}, m_{y}$, and $m_{z}$ are the principal moments of inertia, holds true. The structure of such a solution is shown schematically in Fig. 1, where circles stand for solvent molecules and straight segments for polymer ones.

The examined model corresponds to aqueous solutions of cellulose derivatives. Therefore, the mechanisms of the mentioned structural transition will be studied on an example of the cellulose derivative, hy-

ISSN 2071-0194. Ukr. J. Phys. 2020. Vol. 65, No. 1 
droxypropyl methylcellulose (metolose) [3]. To some extent, this article continues our work [4].

Talking about the challenging character of the researched problem, it should be noted that the role of aqueous solutions of cellulose derivatives as a successful implementation of the model of rod-like molecules is not the only feature that attracts the attention of researchers. The scope of researches dealing with those objects permanently expands (see, e.g., works [5-7] and references therein), because cellulose may turn out a unique inexhaustible resource applicable for the solution of many practical problems of the mankind.

\section{Forms of Molecules and Their Clusters in a Solution}

The form of molecules in a solution was determined according to the data of the viscometric experiment (the relevant procedure was described in work [4]). Aqueous solutions of metolose manufactured by the Shin-Etsu Chemical Company (Hypromellose USP, Substitution Type 2906, Grade 65SH-50) were studied [3]. The temperature dependences of the viscosity of examined solutions are shown in Fig. 2. The obtained experimental data were interpreted in the framework of the hydrodynamic solution theory [8], where the solution is considered as a continuous liquid medium containing absolutely hard inclusions.

The solution viscosity at a constant temperature can be described by the power series

$\eta=\eta_{0}\left(1+\sum_{m=1}^{\infty} b_{m} c_{\nu}^{m}\right)$,

where $\eta_{0}$ is the viscosity of water, and $c_{\nu}$ the volume fraction of metolose. In calculations, we used a value of $1.39 \times 10^{3} \mathrm{~kg} / \mathrm{m}^{3}$ for the metolose density [3].

The inclusions were assumed to be ellipsoids of rotation. In this case, the following expressions were obtained for the coefficient $b_{1}$ in expansion (5):

$b_{1}=2.5+0.4075(p-1)^{1.508}$,

if $1<p<15$, and

$b_{1}=1.6+\frac{p^{2}}{5}\left[\frac{1}{3(\ln 2 p-1.5)}+\frac{1}{\ln 2 p-0.5},\right]$

if $p>15$. Here, $p=a_{1} / a_{2}$ is the ratio between the major, $a_{1}$, and minor, $a_{2}$, respectively, semiaxes of the ellipsoid.

ISSN 2071-0194. Ukr. J. Phys. 2020. Vol. 65, No. 1

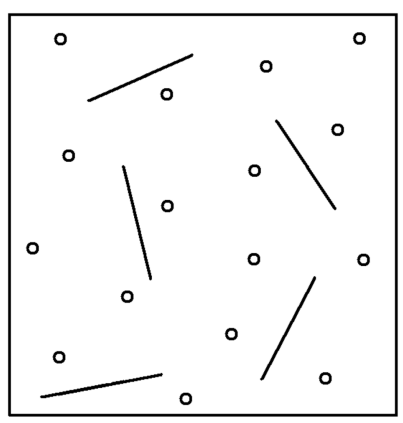

Fig. 1. Structural model for a solution of rod-like molecules

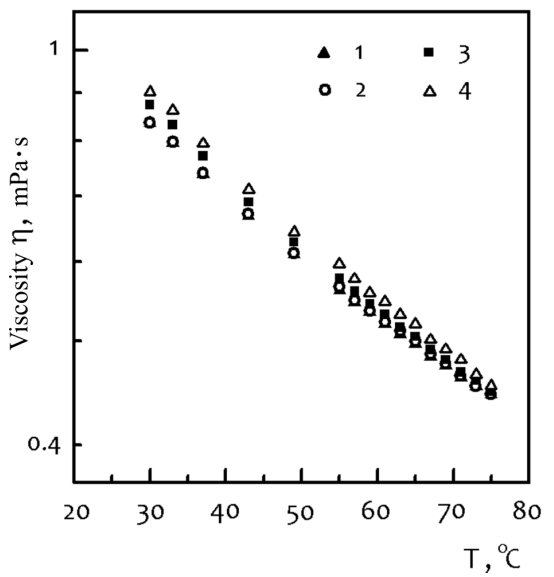

Fig. 2. Temperature dependences of the viscosity of metolose aqueous solutions with concentrations of 0.05 (1), 0.1 (2), 0.2 (3), and $0.4 \mathrm{~g} / \mathrm{l}(4)$

The temperature dependence of the ratio $p$ was calculated with the use of relations (6) and (7) in accordance with the data depicted in Fig. 3, a. The result of calculations is shown in Fig. 3, $b$.

According to the certified values for the test specimens, the length of a totally straightened molecule equals $L \approx 300 \mathrm{~nm}$. As the effective thickness of this molecule, we took $d=0.8 \mathrm{~nm}$, which is equal to the interchain distance in the crystalline lattice of cellulose [10].

When being dissolved in water, metolose decays into separate molecules, so that every inclusion is a separate molecule at a temperature of $30^{\circ} \mathrm{C}$. Taking into account that metolose molecules are rather rigid objects, we may assume that they have a completely straightened configuration in the solution at that temperature. In this case, $a_{1}=L$ and $a_{2}=d$. From whence, taking into account the values given 


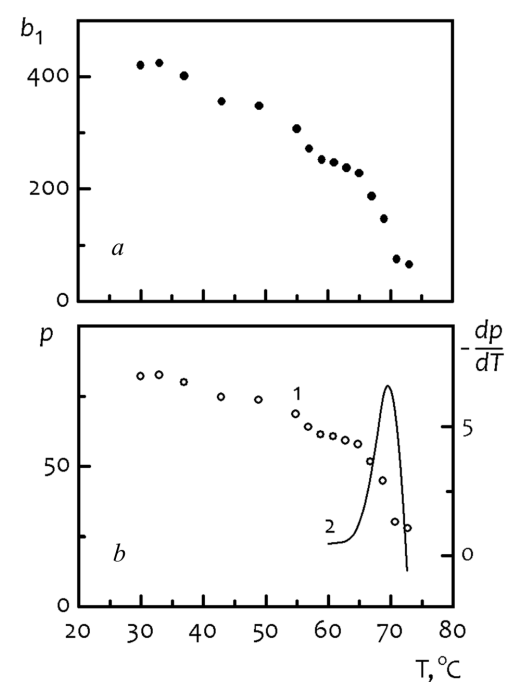

Fig. 3. Temperature dependences of the quantities characterizing metulose aqueous solutions: the coefficient $b_{1}$ in formula (5) (a), the ratio $p$ between the semi-axes of the ellipsoid of rotation in formulas (6) and (7) (symbols 1 ) and the derivative $-d p / d T$ in the interval $T=(60 \div 75)^{\circ} \mathrm{C}$ (curve 2) $(b)$. The root-mean-square errors of the calculated $b_{1}$ and $p$ values do not exceed $15 \%$

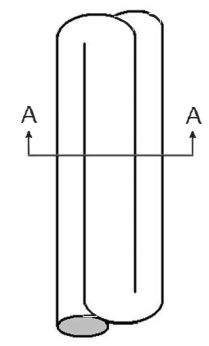

$a$

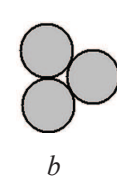

$b$

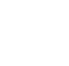

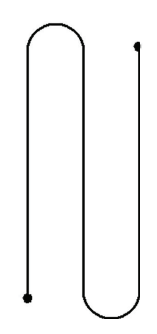

$c$
Fig. 4. Form of the metolose molecule in the solution: top view $(a)$, AA cross-section $(b)$, projection of the chain axis onto a plane $(c)$

above, we obtain the estimate $p \approx 370 \mathrm{~nm}$. However, this value significantly exceeds the $p$-value estimated experimentally (see Fig. 3, b). Therefore, we may argue that the molecules collapse. Agreement with the experiment can be reached, if we assume that the molecules become double-folded (Fig. 4). Accordingly, the external contours of this configuration form an ellipsoid of rotation with values of 100 and $1.3 \mathrm{~nm}$ for the semiaxes. Let the configuration of a macromolecule shown in Fig. 4 be referred to as a rod.

As one can see from Fig. 3, b, the parameter $p$, which characterizes the shape of ellipsoidal inclusions,

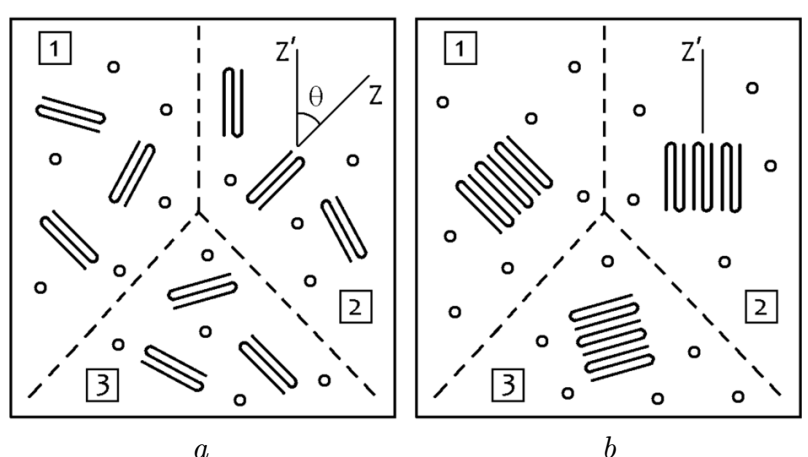

Fig. 5. Schematic diagrams of the structure of metolose aqueous solution at temperatures of $30^{\circ} \mathrm{C}(a)$ and $75^{\circ} \mathrm{C}(b)$

decreases with the increasing temperature. Let us suppose that this decrease is associated with a change in the rod shape. This change can only result from the appearance of new bends in the molecule. However, as was mentioned above, a metolose molecule has a considerable rigidity. Therefore, it is reasonable to assume that the observed decrease takes place due to the formation of clusters.

Those clusters arise, when the rods become packed in parallel to one another. It is evident that the most dense package is achieved provided that the cluster size is constant and equal to the rod length $a_{1}$. The value $p \approx 20$ observed at a temperature of $75{ }^{\circ} \mathrm{C}$ is realized, if the number of cores composing a cluster is approximately equal to 11-12. The relevant schematic diagrams for the structure of the aqueous solution of metolose at 30 and $75^{\circ} \mathrm{C}$ are exhibited in Fig. 5.

\section{Local Character of Structural Transition}

The parallel packing of rods in the clusters means that there emerge orientational elements of ordering in the system. In other words, the observed temperatureinduced change in the parameter $p$ testifies to a structural transition in the solution, when the disordered phase (the solution with the solute in the form of rodlike macromolecules) transits into an ordered one (the solution with the solute in the form of clusters). Accordingly, the temperature at which the derivative $-d p / d T$ reaches its maximum should be taken as the phase transition temperature. In agreement with Fig. 3, $b$, this temperature equals $(69 \pm 1)^{\circ} \mathrm{C}$.

The degree of ordering is usually characterized by indicating the value of the order parameter. Let us 
define the order parameter notion for the structures depicted in Fig. 5. It is known [11] that the thermodynamic potential of the system $\Phi$ can be written as the sum

$\Phi=\sum_{j} \tilde{\phi}_{j} \Delta v_{j}$

In this form, $\Phi$ is regarded as the sum of thermodynamic potentials of subsystems. Each $j$-th subsystem occupies "its" volume $\Delta v_{j}$, which is called the infinitesimal physical volume. This subsystem is in a local equilibrium state characterized by the thermodynamic potential $\phi_{j}=\tilde{\phi}_{j} \Delta v_{j}$. In other words, the volume occupied by the system is divided into domains with the volumes $\Delta v_{j}$, with the local equilibrium being established in each of them.

For instance, let the areas separated by dashed lines and marked by the numbers 1, 2, and 3 in Fig. 5 be such domains in the aqueous solution of metolose. As an example, let us consider domain 2. At a temperature of $30{ }^{\circ} \mathrm{C}$, the minimum of the thermodynamic potential $\phi_{2}=\tilde{\phi}_{2} \Delta v_{2}$ of this domain corresponds to the situation where, as is shown in Fig. 5, the rods are located separately from one another. At a temperature of $75{ }^{\circ} \mathrm{C}$, the thermodynamic potential is minimum, when the same rods in the same domain are combined into a cluster.

Let us denote the axes directed along the axes of the chains in the rod and in the cluster as $Z$ and $Z^{\prime}$, respectively, and the angle between them as $\theta$ (Fig. 5). Let us also introduce into consideration the local (for the $j$-th domain) parameter of orientational order [1]

$S_{j}=\frac{1}{2}\left(3\left\langle\cos ^{2} \theta\right\rangle_{j}-1\right)$,

where

$\left\langle\cos ^{2} \theta\right\rangle_{j}=\frac{1}{N_{j}} \sum_{n=1}^{N_{j}} \cos ^{2} \theta_{n}$,

and $N_{j}$ is the number of rods in the $j$-th domain. If the rods are separated from one another, then $S_{j}<1$. But if they are combined into a cluster, we have $S_{j}=1$. Thus, by introducing the local order parameter into consideration, we obtain a possibility to describe the process of establishing the orientational ordering in each domain that plays the role of physically infinitesimal volume.
Let $\phi_{j}^{\prime}$ and $\phi_{j}^{\prime \prime}$ be the thermodynamic potentials for the $j$-th domain in the cases where the rods exist separately and where they are integrated into a cluster, respectively. By definition, those potentials are temperature-dependent:

$\phi_{j}^{\prime}=\phi_{j}^{\prime}(T)$,

$\phi_{j}^{\prime \prime}=\phi_{j}^{\prime \prime}(T)$.

The temperature $T_{0}$ above which a cluster is formed is determined by the equality

$\phi_{j}^{\prime}\left(T_{0 j}\right)=\phi_{j}^{\prime \prime}\left(T_{0}\right)$.

If $T<T_{0 j}$, then $\phi_{j}^{\prime}<\phi_{j}^{\prime \prime}$, and the rods exist separately. Otherwise, i.e., if $T>T_{0 j}$, then we have $\phi_{j}^{\prime}>\phi_{j}^{\prime \prime}$, and the rods form a cluster. The formation of a cluster results in a jump of the order parameter from a certain value $S_{j}<1$ to 1 . Such a jump-like variation of the order parameter is typical of the phase transitions of the first kind. Therefore, when the value of this parameter changes from $S_{j}<1$ to 1 in a subsystem with the volume $\Delta v_{j}$, the first-order phase transition occurs. From this point of view, the clustering in the $j$-th domain has attributes of the first-order phase transition. Since this transition takes place in a separate domain, it is reasonable to call it local.

The formation of clusters - or, equivalently, local phase transitions - also occurs in other domains (physically infinitesimal volumes), as is illustrated in Fig. 5. Taking the whole system into account, the clustering should be considered as a common phase transition. But this transition is a set of local phase transitions. Generally speaking, the temperatures $T_{0 j}$ of those transitions can be different. As a result, if we talk about the clustering as a common phase transition, its temperature will be "smeared" over a certain interval, so that a certain average temperature $\langle T\rangle$ from this interval should be chosen as the phase transition temperature. Earlier, we took the temperature corresponding to the maximum of the derivative $-d p / d T$ as the temperature $\langle T\rangle$.

As one can see, the system becomes ordered after the formation of clusters, but this ordering is local. Let us introduce a laboratory frame attached to a device for measuring the viscosity. Let the axis $Z^{\prime \prime}$ of this frame be directed along a capillary with the researched liquid. The variable $\theta^{\prime}$ is used to describe 
the angle between this axis and the $Z$-axis of every cluster. Now, the matter concerns the orientational order in the location of clusters, which is characterized by the order parameter

$S^{\prime}=\frac{1}{2}\left(3\left\langle\cos ^{2} \theta^{\prime}\right\rangle-1\right)$.

It is evident that the formed clusters remain disoriented, so that the parameter $S^{\prime}$ is less than unity.

Hence, if we consider the orientation process for the chains that enter the composition of both the rods and clusters, we may say that the chains undergo a local orientation, when the temperature $\langle T\rangle$ is exceeded. At this point, the ordering process terminates, but the set of chains remains disordered with respect to the whole system.

\section{Conclusions}

On an example of metolose aqueous solutions, it is shown that a structural phase transition takes place in a dilute solution of rod-like macromolecules. This phase transition is characterized by the following specific features:

1) the structure ordering takes place: the disordered phase transforms into an ordered one;

2) the transition takes place in a certain temperature interval; the ordered phase exists above this interval, and the disordered phase below it; for metolose aqueous solutions, this interval equals $60 \div 75^{\circ} \mathrm{C}$;

3 ) the disordered phase is a solution in which the solute exists in the form of separate molecules; in aqueous solutions of metolose, such molecules look like rods formed by double-folded chains of metolose; the length of such rods is $100 \mathrm{~nm}$, and their thickness equals $1.5 \mathrm{~nm}$;

4) the ordered phase is a solution in which the solute exists in the form of clusters; in aqueous solutions of metolose, every cluster consists of 11-12 rods oriented in parallel to each other;

5) the observed structural transition has a character of the first-order phase transition; it is a set of local transitions of the first kind occurring in physically infinitesimal volumes;

6) the local phase transition is characterized by the orientational order parameter; it results in the formation of a cluster; this transition is accompanied by a jump in the orientational order parameter;

7) due to the structural transition, there arises a local orientational order in the location of rod-like molecules; this ordering manifests itself in the existence of clusters.

The authors are grateful to the Harke Group (Germany) for metolose specimens kindly provided for researches.

1. P.G. de Gennes, J. Prost. The Physics of Liquid Crystals (Oxford University Press, 1993) [ISBN: 978-0-19-852024-7].

2. L. Onsager. The effects of shape on the interaction of colloidal particles. Ann. N.Y. Acad. Sci. 51, 627 (1949).

3. Metolose/Shin-Etsu Chemical Co., Ltd (Japan) [http:// www.metolose.jp/en/industrial/metolose.html].

4. O.M. Alekseev, Yu.F. Zabashta, V.I. Kovalchuk, M.M. Lazarenko, L.A. Bulavin. The structure of polymer clusters in aqueous solutions of hydroxypropylcellulose. Ukr. J. Phys. 64, 238 (2019).

5. K.M. Kovalov, O.M. Alekseev, M.M. Lazarenko, Yu.F. Zabashta, Y.E. Grabovskii, S.Y. Tkachov. Influence of water on the structure and dielectric properties of the microcrystalline and nano-cellulose. Nanoscale Res. Lett. 12, 468 (2017).

6. K. Kamide. Cellulose and Cellulose Derivatives (Elsevier Science, 2005) [ISBN: 978-0-444-82254-3].

7. T. Heinze, O. El Seoud, A. Koschella. Cellulose Derivatives: Synthesis, Structure, and Properties (Springer, 2018) [ISBN: 978-3-319-73167-4].

8. L.D. Landau, E.M. Lifshitz. Course of Theoretical Physics, Vol. 6: Fluid Mechanics (Elsevier, 2013) [ISBN: 978-0-75062767-2].

9. W. Kuhn, H. Kuhn. Die Abhängigkeit der Viskosität vom Strömungsgefälle bei hochverdünnten Suspensionen und Lösungen. Helv. Chim. Acta. 28, 97 (1945).

10. B. Wunderlich. Macromolecular Physics (Academic Press, 2013) [ISBN: 978-0-127-65603-8].

11. L.D. Landau, E.M. Lifshitz. Course of Theoretical Physics, Vol. 5: Statistical Physics (Elsevier, 2013) [ISBN: 978-0750-63372-7].

Received 18.05.19

Translated from Ukrainian by O.I. Voitenko

О.М. Алексеєв, Ю.Ф. Забашта, В.І. Ковалъчук,

М.М. Лазаренко, Є.Г. Рудніков, Л.А.Булавін

СТРУКТУРНИЙ ПЕРЕХІД У РОЗБАВЛЕНИХ РОЗЧИНАХ СТРИЖНЕПОДІБНИХ МАКРОМОЛЕКУЛ

Р е з ю м е

На основі даних віскозимеричного експерименту, проведеного для водних розчинів гідроксипропілметилцелюлози (метолози), встановлено, що в розбавлених розчинах стрижнеподібних макромолекул із збільшенням температури відбувається структурний перехід, у процесі якого молекули утворюють кластери, розташовуючись у них параллельно одна до одної. Показано, що цей перехід носить характер фазового переходу першого роду і є сукупністю локальних переходів того ж типу.

ISSN 2071-0194. Ukr. J. Phys. 2020. Vol. 65, No. 1 